\title{
PUSHOVER, CYCLIC AND DYNAMIC ANALYSES OF RC SHEAR WALLS BY MEANS OF PARC_CL1.1 CRACK MODEL
}

\author{
BEATRICE BELLETTI ${ }^{*}$, MATTEO SCOLARI ${ }^{\dagger}$ AND FRANCESCA VECCHI ${ }^{\dagger \dagger}$ \\ 'University of Parma \\ Parma, Italy \\ e-mail: beatrice.belletti@unipr.it \\ ${ }^{\dagger}$ University of Parma \\ Parma, Italy \\ e-mail: scolari.matteo87@gmail.com \\ ${ }^{\dagger \dagger}$ University of Parma \\ Parma, Italy \\ e-mail: vecchi.francesca89@gmail.com
}

Key words: Shell elements, multi-layered, shell modeling, NLFEA, shear wall, PARC_CL, crack model

\section{ABSTRACT}

In this paper the PARC_CL1.1 model (implemented in the user subroutine UMAT.for in Abaqus Code) is presented and applied to the non-linear finite element analyses (NLFEA) of reinforced concrete (RC) shear walls tested, by means of pseudo dynamic test (PSD), at the European Laboratory for Structural Assessment (ELSA, Joint Research Centre) within the project SAFE [1][4]. These experimental tests are included as part of CASH benchmark, which is an international benchmarking program organised under an initiative of the OEDC-NEA (Nuclear Energy Agency). The main objective of CASH benchmark is to evaluate the reliability of predictive analysis tools and methods as well engineering practice know how to assess the seismic capacity of reinforced concrete shear walls to withstand strong earthquakes considered for beyond design situation.

The PARC_CL1.1 crack model is the extension of the previous PARC model [5]-[6], and allows to consider cyclic loads and plastic deformations in the unloading phase. The PARC_CL1.1 model is based on a fixed crack approach and smeared approach for the reinforcements.

The shear walls tested at the ELSA have been used to validate the proposed PARC_CL1.1 crack model; the shear walls have been modeled using multi-layered shell elements and NLFEA have been carried out considering several loading condition (static pushover, cyclic and dynamic).

\section{INTRODUCTION}

Non-linear finite element analyses are nowadays increasingly used both in design practice and scientific field. In new standard codes and guidelines this type of analysis is proposed as a method of verification alternative and more powerful than the analytical calculation [7]-[8].
In civil engineering different types of structural members are suitable to be analyzed by means of NLFEA; in particular this paper is focalized on Reinforced Concrete (RC) shear walls, which are widely used in precast concrete blocks buildings and in power plant facilities [9]. Many experimental programs have been driven through the last 40 years to investigate the nonlinear behaviour of $\mathrm{RC}$ 
shear walls subjected to horizontal forces.

Experimental tests, as reviewed by Wood [10] and Martinelli [11], have been carried out mainly considering monotonic, repeated and alternating loading. Recently, tests have been run, for example by Pilakoutas and Elnashai [12], on specimens with aspect ratio equal to 2 subjected to severe cyclic loading and by Palermo and Vecchio [13] on squat flanged shear walls under cyclic displacement.

Few pseudo-dynamic tests are available in literature. Naze and Sidaner [14] analysed, within the SAFE project, the dynamic behaviour of very squat walls (with aspect ratio 0.4); also Mazars et al. [15] conducted significant studies, starting from the results of the SAFE project tests.

Furthermore, round robin competitions and blind prediction were recently organized and are in progress nowadays to investigate the prediction capacity of NLFE tools (e.g. ConCrack benchmark [16], SMART-2013 [17], CASH benchmark [18]).

ConCrack shear wall [16] was analyzed at the University of Parma, with pushover analyses, both using the PARC_CL crack model, implemented in ABAQUS code, and the software DIANA, as reported in [19]. Further application of the PARC_CL model to pushover analysis of RC structural wall buildings can be found in [20].

SMART-2013 project [17] investigated the dynamic behaviour of a 1:4 scale irregular RC wall structure, subjected to strong-motion seismic inputs. Non-linear dynamic analyses were been carried out adopting the PARC_CL crack model in [21].

Finally, in this paper, a new release of the PARC_CL crack model, named PARC_CL1.1, which allows to take into account plastic deformation in the unloading phase, is presented. The new release of the model is validated by comparison with the experimental results proposed within CASH benchmark [18]. CASH benchmark is an international benchmarking program organized under an initiative of the OEDC-NEA (Nuclear Energy Agency). The main objective of CASH is to evaluate the reliability of predictive analysis tools and methods as well as engineering practice know how to assess the seismic capacity of reinforced concrete shear walls. The CASH benchmark consists of two phases. The first phase, based on the "SAFE" experimental campaign [1]-[4], invited to calibrate the adopted numerical model by means of different analyses (static pushover, static cyclic and dynamic). During the second phase, the participants would have to assess the capacity of a scale 1 shear wall extracted from an NPP building.

In this paper some results obtained on the phase 1 of the CASH benchmark is presented. The new PARC_CL1.1 crack model, adopted for the analysis, is also presented.

\section{EXPERIMENTAL PROGRAM}

The phase 1 of the CASH benchmark, presented in this paper, is based on the SAFE experimental campaign carried out at the JRC Ispra Laboratory in Italy [22]. The SAFE experimental campaign consists of a series of pseudo-dynamic (PSD) tests on 13 different shear walls. In particular, for the purpose of phase 1, T6, T7, T8 and T9 [1]-[4] shear walls were selected.

All the specimens have the same geometrical properties: a length $l=3000 \mathrm{~mm}$ an height $h=1200 \mathrm{~mm}$ and a thickness $t=200$ $\mathrm{mm}$. In order to reproduce the effect of perpendicular walls, at both the ends of each specimen two flanges were added. The top and the bottom part of the specimen are made of rigid concrete beams (Figure 1).

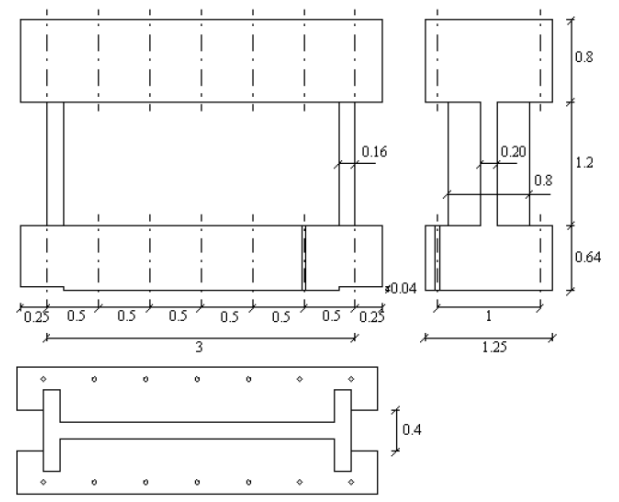

Figure 1 - Geometrical properties for T6, T7, T8 and T9 shear walls (dimension in $\mathrm{m}$ ).

The differences in the specimens are in 
percentage of steel, $\rho$, in vertical compressive stress, $\sigma_{v}$, in the numerical mass applied in the PSD test, $M_{N}$, and in the first vibration frequency, $f$. The mechanical and geometrical properties of the specimens are listed in Table 1.

Table 1 - Mechanical and geometrical properties of the specimens.

\begin{tabular}{|c|c|c|c|c|}
\hline & T6 & T7 & $\mathrm{T} 8$ & T9 \\
\hline \multicolumn{5}{|l|}{ Geometry } \\
\hline $\mathrm{b}[\mathrm{mm}]$ & 3000 & 3000 & 3000 & 3000 \\
\hline $\mathrm{h}[\mathrm{mm}]$ & 1200 & 1200 & 1200 & 1200 \\
\hline $\mathrm{t}[\mathrm{mm}]$ & 200 & 200 & 200 & 200 \\
\hline \multicolumn{5}{|l|}{ Concrete } \\
\hline $\mathrm{f}_{\mathrm{cm}}[\mathrm{Mpa}]$ & 33.1 & 36.4 & 28.6 & 35.7 \\
\hline $\mathrm{f}_{\mathrm{ctm}}[\mathrm{Mpa}]$ & 3.1 & 3.3 & 2.8 & 3.3 \\
\hline $\mathrm{E}_{\mathrm{c}, \mathrm{MC} 2010}[\mathrm{Gpa}]$ & 31.9 & 32.9 & 30.4 & 32.7 \\
\hline \multicolumn{5}{|l|}{ Steel } \\
\hline Horizontal rebar & $\Phi 10 @ 125$ & $\Phi 10 @ 125$ & $\Phi 8 @ 125$ & $\Phi 8 @ 125$ \\
\hline$\rho_{\mathrm{H}}[\%]$ & 0.628 & 0.628 & 0.402 & 0.402 \\
\hline $\mathrm{f}_{\mathrm{ym} \text {-horizontal }}[\mathrm{Mpa}]$ & 572.8 & 572.8 & 594.4 & 594.4 \\
\hline $\mathrm{f}_{\text {tm-horizontal }}[\mathrm{Mpa}]$ & 651.0 & 651.0 & 672.0 & 672.0 \\
\hline $\mathrm{E}_{\mathrm{s}-\text { horizontal }}[\mathrm{Gpa}]$ & 205 & 205 & 205 & 205 \\
\hline Vertical rebar & $\Phi 8 @ 125$ & $\Phi 8 @ 125$ & $\Phi 8 @ 125$ & Ф8@125 \\
\hline$\rho_{\mathrm{V}}[\%]$ & 0.402 & 0.402 & 0.402 & 0.402 \\
\hline $\mathrm{f}_{\mathrm{ym} \text {-vertical }}[\mathrm{Mpa}]$ & 594.4 & 594.4 & 594.4 & 594.4 \\
\hline $\mathrm{f}_{\text {tm-vertical }}[\mathrm{Mpa}]$ & 672.0 & 672.0 & 672.0 & 672.0 \\
\hline $\mathrm{E}_{\mathrm{s} \text {-vertical }}[\mathrm{Gpa}]$ & 205 & 205 & 205 & 205 \\
\hline
\end{tabular}

The modulus of elasticity of concrete was not directly obtained by tests but was derived adopting the formulation proposed in fib Model Code 2010, Eq.(1):

$$
E_{C, M C 2010}=21500 \cdot\left(\frac{f_{c m}}{10}\right)^{1 / 3}
$$

Consequently, assuming a Poisson's ratio equal to 0.2 the conventional isotropic shear modulus for concrete, $G$, could be derived.

The analytical shear stiffness of the wall, $K_{A}$, is evaluated with Eq.(2):

$$
K_{A}=\frac{G \cdot(b \cdot t)}{h}
$$

where $b, t, h$ represent the base, the thickness and the height of the wall, respectively.

Finally, knowing the mass of each wall, $M$, (considered as the sum of physical mass, $M_{P}$, and numerical mass, $M_{N}$ ), the frequency of the wall could be analytically derived. The analytical calculation of the main features of the specimens are listed in Table 2 .

Table 2 - Main features of the specimens: analitycal calculation.

\begin{tabular}{|c|c|c|c|c|c|c|c|c|}
\hline & $\begin{array}{c}\mathrm{b} \\
{[\mathrm{m}]}\end{array}$ & $\mathrm{t}$ & $\mathrm{h}$ & $\mathrm{E}$ & $\mathrm{G}$ & $\mathrm{K}_{\mathrm{A}}$ & $\mathrm{M}$ & $\mathrm{f}_{\mathrm{A}}$ \\
{$[\mathrm{m}]$} & {$[\mathrm{GPa}]$} & {$[\mathrm{GPa}]$} & {$[\mathrm{MN} / \mathrm{m}]$} & {$[\mathrm{ton}]$} & {$[\mathrm{Hz}]$} \\
\hline $\mathrm{T} 6$ & 3 & 0.2 & 1.2 & 31.9 & 13.3 & 6649 & 1252 & 11.6 \\
\hline $\mathrm{T} 7$ & 3 & 0.2 & 1.2 & 32.9 & 13.7 & 6861 & 11272 & 3.9 \\
\hline $\mathrm{T} 8$ & 3 & 0.2 & 1.2 & 30.4 & 12.7 & 6336 & 1252 & 11.3 \\
\hline $\mathrm{T} 9$ & 3 & 0.2 & 1.2 & 32.7 & 13.6 & 6817 & 11272 & 3.9 \\
\hline
\end{tabular}

The experimental tests have been carried out by means of Pseudo-Dynamic (PSD) tests using the same reference input motion for all the specimens, reported in Figure 2.

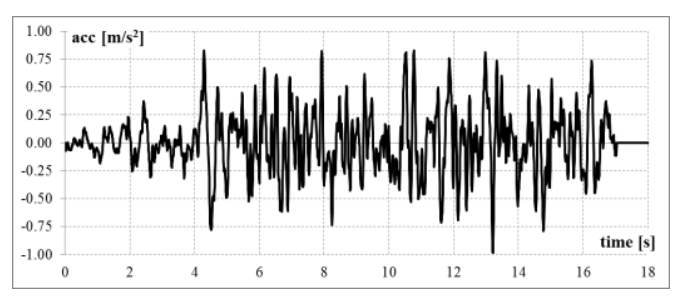

Figure 2 - Reference input motion for PSD tests

For each specimen 4 sequentially runs have been applied, adopting for each run the amplification factor of the reference input motion reported in Table 3.

Table 3 - Main characteristics of experimental set-up

\begin{tabular}{|r|r|r|r|r|}
\hline & $T 6$ & $T 7$ & $T 8$ & $T 9$ \\
\hline Vertical stress, $\sigma_{\mathrm{v}}[\mathrm{Mpa}]$ & 1.01 & 1.01 & 0.32 & 0.32 \\
\hline Pysichal Mass, $\mathrm{M}_{\mathrm{P}}[\mathrm{t}]$ & 25 & 25 & 25 & 25 \\
\hline Numerical Mass, $\mathrm{M}_{\mathrm{N}}[\mathrm{t}]$ & 1227 & 11247 & 1227 & 11247 \\
\hline Reference input loading amplication factor \\
\hline RUN 1 & 1.0 & 1.0 & 1.0 & 1.0 \\
\hline RUN 2 & 1.3 & 1.0 & 1.4 & 3.0 \\
\hline RUN 3 & 1.5 & 2.0 & 1.8 & 6.0 \\
\hline RUN 4 & 1.8 & 10.0 & - & 10.0 \\
\hline
\end{tabular}

Prior to run the experimental PSD tests, the eigenfrequency of each specimen, $f_{\text {exp }}$, was measured by low level vibration and the corresponding elastic stiffness, $K_{\text {exp }}$, was derived. The obtained experimental results and the comparison with the analytical values are reported in Table 4. 
Table 4 - Main features of the specimens: comparison between analytical calculation and experimental results.

\begin{tabular}{|c|c|c|c|c|c|c|}
\hline \multicolumn{2}{|c|}{} & \multicolumn{2}{|c|}{ Analytical } & \multicolumn{2}{|c|}{ Experimental } & \\
\hline & $\begin{array}{c}\mathrm{M} \\
{[\text { ton }]}\end{array}$ & $\begin{array}{c}\mathrm{K}_{\mathrm{A}} \\
{[\mathrm{MN} / \mathrm{m}]}\end{array}$ & $\begin{array}{c}\mathrm{f}_{\mathrm{A}} \\
{[\mathrm{Hz}]}\end{array}$ & $\begin{array}{c}\mathrm{K}_{\exp } \\
{[\mathrm{MN} / \mathrm{m}]}\end{array}$ & $\begin{array}{c}\mathrm{f}_{\exp } \\
{[\mathrm{Hz}]}\end{array}$ & $\begin{array}{c}\mathrm{K}_{\exp } / \\
\mathrm{K}_{\mathrm{A}}\end{array}$ \\
\hline T6 & 1252 & 6649 & 11.6 & 5348 & 10.4 & 0.80 \\
\hline T7 & 11272 & 6861 & 3.9 & 5767 & 3.6 & 0.84 \\
\hline T8 & 1252 & 6336 & 11.3 & 4557 & 9.6 & 0.72 \\
\hline T9 & 11272 & 6817 & 3.9 & 3742 & 2.9 & 0.55 \\
\hline \multicolumn{3}{|c}{} & \multicolumn{3}{c|}{ Average } & 0.72 \\
\hline
\end{tabular}

Interestingly, the average value of the ratio between the experimental and the analytical stiffness is equal to 0.72 , very close to the 0.7 median value obtained by Sozen and Moehle [23]. According to the results of this preliminary studies in the NLFEA, presented in paragraph 4 , the modulus of elasticity of concrete was reduced by a factor 0.7 with respect to the one calculated according to Eq.(1). In Table 5 the comparison of the main features of the specimens was extended to NLFE results.

In order to apply pure shear to the walls, the rotation of the top beam was prevented adopting two vertical jack positioned at the end of the specimen.

\section{PARC_CL CRACK MODEL}

NLFEA have been carried out using the PARC_CL1.1 crack model (Physical Approach for Reinforced Concrete under Cycling Loading) implemented at the University of Parma as a user subroutine in the software ABAQUS.

The PARC_CL1.1 crack model is a development of the previous PARC models [5]-[6], and allows to consider plastic and irreversible deformations in the unloading phase.

The PARC_CL model is based on a fixed crack approach, in which at each integration point two reference systems are defined: the local $x, y$ coordinate system and the 1,2 coordinate system along the orthotropic axes. The angle between the 1 -direction and the $x$ direction is denoted as $\psi$, whereas $\alpha_{i}=\theta_{i}-\psi$ is the angle between the direction of the $i$-th order of the bar and the x-direction, Figure 3-a.
When the maximum tensile principal stress reaches the tensile strength of concrete $f_{c t}$, cracking starts to develop, and the 1,2 coordinate system is fixed, Figure 3-b.
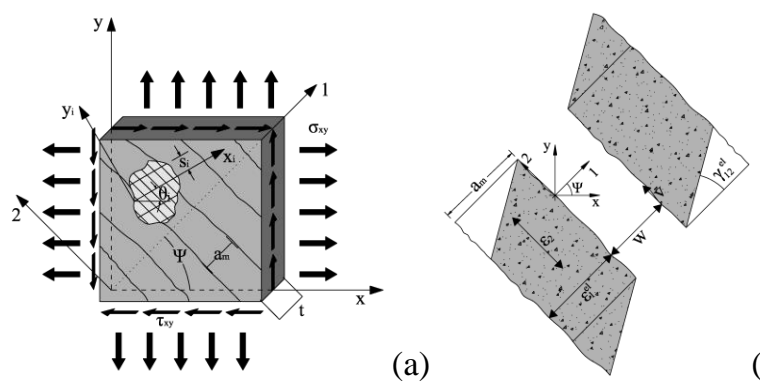

(b)

Figure 3 - (a) RC element subjected to plane stress state and (b) crack parameters

\subsection{Concrete constitutive matrix}

The concrete behaviour is assumed to be orthotropic, both before and after cracking; softening in tension and compression, a multiaxial state of stress and the effect of aggregate interlock are taken into account.

Before cracking the concrete constitutive matrix in the orthotropic directions $(1,2$ coordinate system) is defined in Eq.(3):

$$
\left[\mathrm{D}_{\mathrm{C}}^{1,2}\right]=\left[\begin{array}{ccc}
\frac{E_{C 1}}{\left(1-v_{12} \cdot v_{21}\right)} & v_{21} \cdot \frac{E_{C 1}}{\left(1-v_{12} \cdot v_{21}\right)} & 0 \\
v_{12} \cdot \frac{E_{C 2}}{\left(1-v_{12} \cdot v_{21}\right)} & \frac{E_{C 2}}{\left(1-v_{12} \cdot v_{21}\right)} & 0 \\
0 & 0 & G_{12}
\end{array}\right]
$$

where $E_{C 1}$ and $E_{C 2}$ represent the moduli of elasticity of concrete, respectively in 1 - and 2 direction, in uniaxial condition and $G_{12}$ represents the orthotropic shear modulus. $v_{12}$ and $v_{21}$ represent the Poisson's ratios in the 1 2 plane and they are reduced at the same rate as the corresponding moduli of elasticity, Eq.(4):

$$
v_{12}=v \cdot E_{C 1} / E c \quad v_{21}=v \cdot E_{C 2} / E c
$$

where $E_{C}$ and $v$ represent respectively the initial modulus of elasticity of concrete and the initial Poisson's ratio.

The orthotropic shear modulus, $G_{12}$, is evaluated according to (5): 


$$
G_{21}=\frac{E_{\min }}{2\left(1+v_{12} E_{\min } / E_{C}\right)}
$$

where $E_{\min }$ represents the minimum value between $E_{C 1}$ and $E_{C 2}$.

After cracking, for the whole post-cracking range, the 1-2 coordinate system remains fixed and the Poisson's ratios $v_{12}$ and $v_{21}$ are assumed to be zero, so that the concrete constitutive matrix is defined as in Eq.(6):

$$
\left[\mathrm{D}_{\mathrm{C}}^{1,2}\right]=\left[\begin{array}{ccc}
E_{C 1} & 0 & 0 \\
0 & E_{C 2} & 0 \\
0 & 0 & \beta \cdot G
\end{array}\right]
$$

where $G$ represents the elastic shear modulus and $\beta$ the shear retention factor which allows to take into account the aggregate interlock effect according to Gambarova [24]. The aggregate interlock effect will be discuss briefly in paragraph 3.1.2.

\subsubsection{Cyclic behaviour of concrete}

The uniaxial constitutive model for concrete is reported in Figure 4.

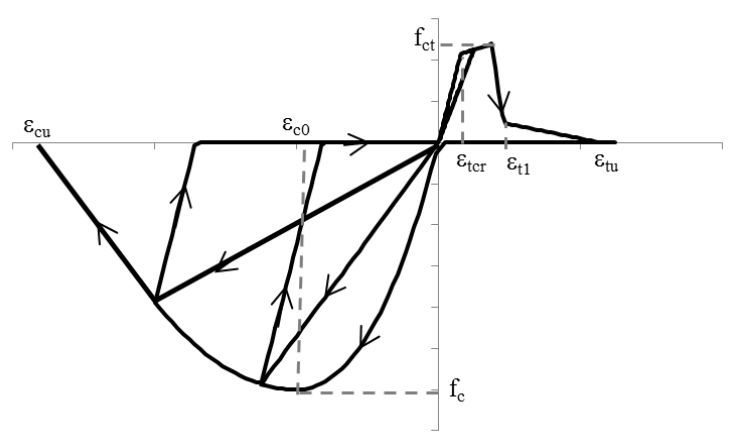

Figure 4 - Constitutive model for concrete

The stress-strain relationship for concrete in tension is defined as a function of its tensile strength, $f_{c t}$, the strain $\varepsilon_{\mathrm{t} 1}$ and $\varepsilon_{\mathrm{tu}}$ (corresponding to residual stress equal to 0.15 $f c t$ and zero, respectively) and the fracture energy, $\mathrm{G}_{\mathrm{F}}$, in tension, calculated according to fib - ModelCode 2010 [8]. The envelope curve for concrete in tension is defined with Eq.(7):

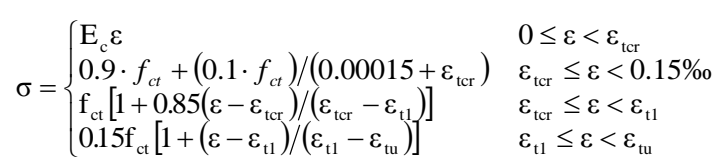

The compressive branch before reaching the peak is defined in agreement with Sargin relation [25] and after the peak with Feenstra relation [26] as a function of the cylinder compressive strength of concrete, $f_{c}$, and concrete fracture energy in compression $G_{C}$ equal to $250 \mathrm{G}_{\mathrm{F}}$. The envelope curve for concrete in compression is defined with Eq.(8):

$$
\sigma= \begin{cases}\frac{\mathrm{E}_{\mathrm{c}} / \mathrm{E}_{\mathrm{c} 0}-\varepsilon / \varepsilon_{c 0}}{1+\left(\mathrm{E}_{\mathrm{c}} / \mathrm{E}_{\mathrm{c} 0}-2\right) \varepsilon / \varepsilon_{c 0}} E_{c 0} \varepsilon & \varepsilon_{c 0} \leq \varepsilon<0 \\ \mathrm{f}_{\mathrm{c}}\left[1-\left(\varepsilon-\varepsilon_{\mathrm{c} 0}\right)^{2} /\left(\varepsilon_{\mathrm{cu}}-\varepsilon_{\mathrm{c} 0}\right)^{2}\right] & \varepsilon_{c u} \leq \varepsilon<\varepsilon_{c 0}\end{cases}
$$

where $E_{c}$ and $E_{c 0}$ are the initial modulus of elasticity and the secant modulus corresponding to the concrete strain at maximum compressive stress, $\varepsilon_{c 0}$, respectively.

Multi-axial state of stress is considered by reducing the compressive strength and the corresponding peak strain due to lateral cracking, as given in Eq. (9), according to [27]:

$$
\zeta=1 /\left(0.85-0.27 \varepsilon_{1} / \varepsilon_{c 0}\right)
$$

being $\varepsilon_{1}$ the tensile strain along 1 -direction and $\varepsilon_{\mathrm{c} 0}$ the concrete strain at maximum compressive stress in case of uniaxial compression.

\subsubsection{Aggregate interlock effect}

The shear behaviour of concrete after cracking allows to take into account the aggregate interlock effect using the formulation proposed by Gambarova [24]. The shear behaviour due to aggregate interlock effect is evaluated on the basis of the crack width, $w$, and the crack sliding, $v$, as shown in Figure 5.

From the shear-crack sliding curve (Figure 5) the shear behavior after cracking is defined. The shear modulus in cracked phase is formulated as a function of $\beta$-factor (Figure 6) multiplied time the elastic shear modulus, $G$, for isotropic material and inserted in the 
constitutive matrix in Eq.(6).

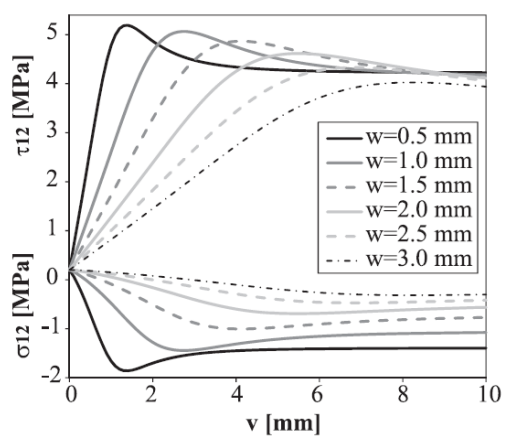

Figure 5 - Gambarova's relationship for aggregate interlock effect [24].

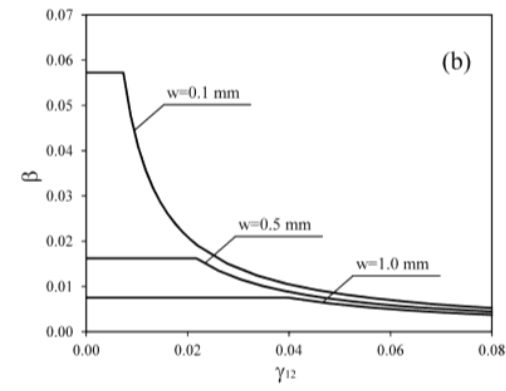

Figure 6 - Shear retention factor in cracked phase for different values of crack opening width.

In the unloading phase the shear- crack sliding behaviour follow the same relationship as for the loading phase.

\subsection{Steel constitutive matrix}

The reinforcement is modelled through a smeared approach and perfect bond is assumed between concrete and steel; the steel behaviour is defined in the $x_{i}, y_{i}$ coordinate system and the steel stiffness matrix is presented in Eq.(10):

$$
\left[\mathrm{D}_{\mathrm{S}}^{\mathrm{xi}, \mathrm{yi}}\right]=\left[\begin{array}{cc}
\rho_{i} \cdot E_{S, i} & 0 \\
0 & 0
\end{array}\right]
$$

where $\rho_{i}$ represents the percentage of steel and $E_{s, i}$ represents the secant elastic modulus of steel.

Eq.(10) shows that the behaviour of steel is defined only along the axis of the bar, it means that the dowel action effect is not taken into account.

The secant elastic modulus of steel $\left(E_{s, i}\right)$ is defined considering an elasto-plastic behaviour with hardening.

\subsection{Overall constitutive matrix}

The overall constitutive matrix in the $x, y$ coordinate system, $\left[\mathrm{D}^{(\mathrm{x}, \mathrm{y})}\right]$, is obtained by assuming that concrete and reinforcement behave like two springs placed in parallel, Eq.(11):

$$
\left[\mathrm{D}^{\mathrm{x}, \mathrm{y}}\right]=\left[\mathrm{T}_{\varepsilon}\right]^{\mathrm{T}}\left[\mathrm{D}_{\mathrm{c}}^{1,2}\right]\left[\mathrm{T}_{\varepsilon}\right]+\left[\mathrm{T}_{\theta \mathrm{i}}\right]^{\mathrm{T}}\left[\mathrm{D}_{\mathrm{s}}^{\mathrm{x}_{\mathrm{i}}, \mathrm{y}_{\mathrm{i}}}\right]\left[\mathrm{T}_{\theta \mathrm{i}}\right]
$$

The transformation matrixes $\left[T_{\varepsilon}\right]$ and $\left[T_{\theta i}\right]$ are used to rotate the concrete matrix from the 1,2 to the $x, y$ coordinate system and the steel matrix from the $x_{i}, y_{i}$ to the $x, y$ coordinate system, respectively.

Finally, the stresses $\left\{\sigma_{(x, y)}\right\}$ in the $x, y$ coordinate system are defined by multiplying the stiffness matrix $\left[\mathrm{D}^{\mathrm{x}, \mathrm{y}}\right]$ time the strain vector $\left\{\varepsilon_{(\mathrm{x}, \mathrm{y})}\right\}$.

\section{NLFEA MODELING}

NLFEA have been carried out with ABAQUS code adopting the PARC_CL1.1 crack model.

All the specimens are modeled using 4 nodes multi-layered shell elements. The Gauss integration scheme is adopted with 4 Gauss integration points (S4); along the thickness each element is divided in 2 layers with 3 Simpson section integration points. Reinforcement is modelled using a smeared approach according to the PARC_CL1.1 crack model prescriptions. The average element length is equal to $100 \mathrm{~mm}$, chosen in order to obtain a value close to the rebar spacing (equal to $125 \mathrm{~mm}$ as shown in Table 1). In Figure 7 is reported a solid view of the mesh adopted for NLFEA. In particular the top and the bottom beams have been modeled using linear elastic material, while the web and the two flanges of the wall have been modeled using PARC_CL1.1 crack model. Furthermore, due to the confining effect of stirrups, the flanges are modeled considering a confinement effects.

As already mentioned three different kinds of analyses have been carried out: static pushover analyses, static cyclic analyses and dynamic time history analyses. Due to some differences in loading and boundary conditions related to the type of analysis the details on 
modeling have been presented in two separated paragraphs.

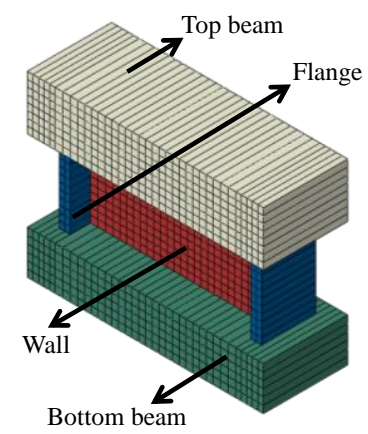

Figure 7 - Solid view of mesh adopted for NLFEA.

\subsection{Static pushover and cyclic analyses}

The boundary and loading conditions applied for static pushover and cyclic analyses are presented in Figure 8.

The translation in the $x$-direction is fixed in correspondence of the anchor elements of the experimental specimens; the translation along the $z$-direction is fixed at the base of the bottom beam and the out-of-plane behaviour is prevented by fixing the translation along the $y$ direction of the whole model.

Load is applied in two different steps: in a first step the self-weight and the vertical pressure is applied; in a second step the horizontal displacement is imposed in correspondence of the section defined "Sec T", Figure 8.

During the experimental tests, in order to apply pure shear condition to the wall, the rotation of the top beam was prevented by means of two vertical jacks. In NLFEA the same condition is obtained by applying a multi-point constraint in "Sec T", Figure 8.

The pushover analyses have been carried out increasing the horizontal displacement till the failure.

The cyclic analyses have been carried out applying to "Sec T" the horizontal displacement measured during the experimental tests.

The implicit method was adopted by the solver while the Newton-Rhapson method was used as convergence criterion. The force and displacement tolerance was fixed to $5 \cdot 10^{-3}$ for forces and $10^{-2}$ for displacements.

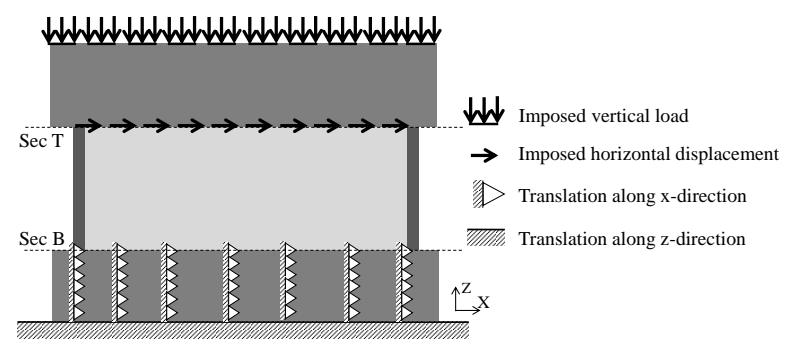

Figure 8 - Boundary and loading conditions for static pushover and cyclic analyses.

\subsection{Dynamic time history analyses}

The boundary and loading conditions applied for dynamic time history analysis are presented in Figure 9.

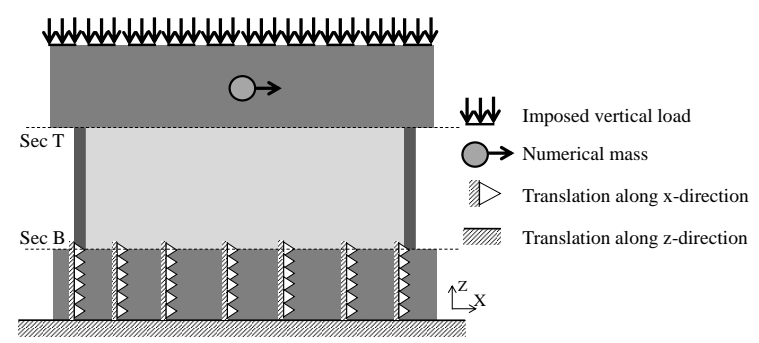

Figure 9 - Boundary and loading conditions for dynamic time history analyses.

The boundary conditions were the same for pushover and cyclic analyses while load is applied in different manner. An additional mass, acting only along $x$-direction, is added in the centroid of the top beam to simulate the numerical mass of the experimental tests.

As for static analyses the load is applied in two different steps: in a first step the selfweight and the vertical pressure is applied; in a second step the horizontal acceleration is imposed and the rotation of the top beam is prevented by applying a multi-point constraint, which imposes the same vertical displacements of the central node of "Sec T" to all the other nodes of "Sec T", Figure 9.

The implicit method was adopted by the solver while the Newton-Rhapson method was adopted as convergence criterion. The time interval adopted was equal to $0.01 \mathrm{~s}$ for nonlinear analysis.

In dynamic analyses two different damping have been adopted: a structural damping and a 
numerical damping.

Structural damping was introduced according to Rayleigh's classical theory defined in Eq.(12):

$$
\xi_{\mathrm{n}}=\frac{\alpha}{2} \frac{1}{\omega_{n}}+\frac{\beta}{2} \omega_{n}
$$

where $\alpha$ represents the mass-proportional damping coefficient, $\beta$ represents the stiffnessproportional damping coefficient, $\omega_{\mathrm{n}}$ represents the natural frequency and $\zeta_{n}$ sets the damping ratio.

At the moment only the mass proportional term $(\alpha)$ can be expressed, as the stiffness proportional term $(\beta)$ is not incorporated in the current version of UMAT subroutine.

The $\alpha$ coefficient (mass proportional damping) is calibrated in order to obtain a damping ratio of $10 \%$ for the frequency of the damaged structure.

Furthermore, a numerical damping is introduced in the model by adopting the Hilber-Hughes-Taylor (HHT) integration scheme [28]. The HHT integration scheme can be considered as an extension of the Newmark integration scheme. Indeed the HHT method uses the same finite difference formulae as the Newmark method, to solve the equation of motion but introduces a parameter $\alpha$ to control the level of numerical dissipation. The $\alpha_{\mathrm{HHT}}$ parameter could assumes a value in between $-0.5<\alpha_{H H T}<0$ and in the current analyses is sets to -0.4 .

\section{NLFEA RESULTS}

Depending on the type of analysis, according to the purpose of CASH benchmark, different specimens have been analyzed. T6 and T8 specimen have been analyzed for pushover, cyclic and dynamic analyses. Dynamic time histories analyses of $\mathrm{T} 7$ and $\mathrm{T} 9$ walls have been added. $\mathrm{T} 7$ and $\mathrm{T} 9$ walls have a numerical mass equal to $11247 \mathrm{t}$, while T6 and T8 walls have a numerical mass equal to 1227 t, Table 3 .

\subsection{Static pushover analyses}

In Figure 10 is reported, for T6 wall, the pushover shear force vs top displacement curves obtained by means of NLFEA and the experimental curve, which represents the result of the Pseudo-Dynamic test.

In Figure 10 the main events registered by NLFEA are marked using different colors, NLFEA results are stopped when the crushing of concrete is reached. Crushing of concrete is achieved when the compressive strain of concrete reaches the ultimate value, $\varepsilon_{c u}$, Figure 4.

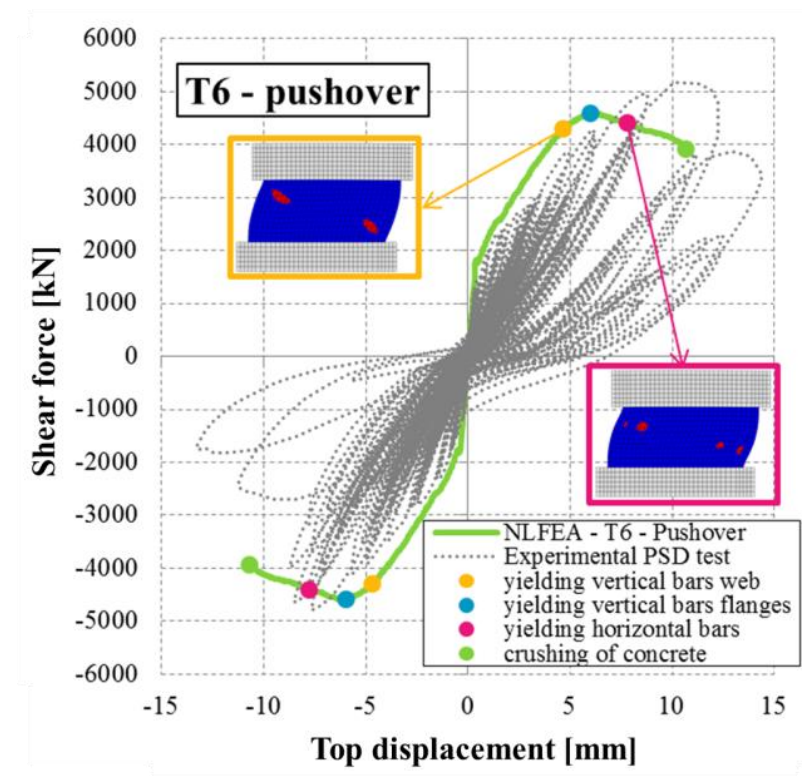

Figure 10 - Static pushover analysis - T6 wall, comparison between NLFEA and experimental results.

Figure 10 shows that at failure both the vertical and the horizontal rebars are yielded.

In Figure 11 is plotted the crack pattern experimentally obtained and the crack pattern evaluated by means of NLFEA. The experimental crack pattern is evaluated at the end of the PSD test, while the NLFEA crack pattern is evaluated at the end of the analysis, when the crushing of concrete occurred.

Figure 11 shows that the crack pattern obtained by means of NLFEA is in agreement with the experimental one. Both in the experimental and NLFEA crack pattern it could be highlighted the compressive diagonal strut, which crushed at failure. 

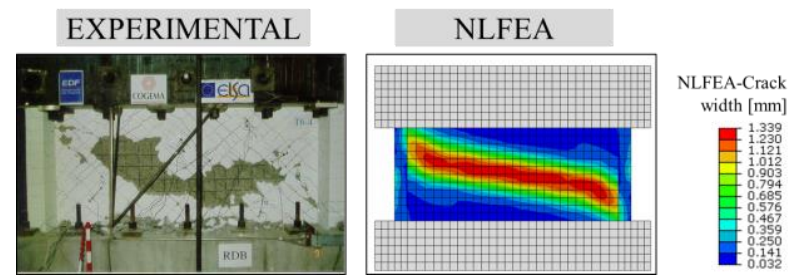

Figure 11 - Comparison between experimental and NLFEA results: crack pattern.

In Figure 12 is reported, for the $\mathrm{T} 8$ specimen, the pushover shear force vs top displacement curve obtained by means of NLFEA compared with the experimental curve. The main events occurred during the NLFEA are marked using different colors in Figure 12.

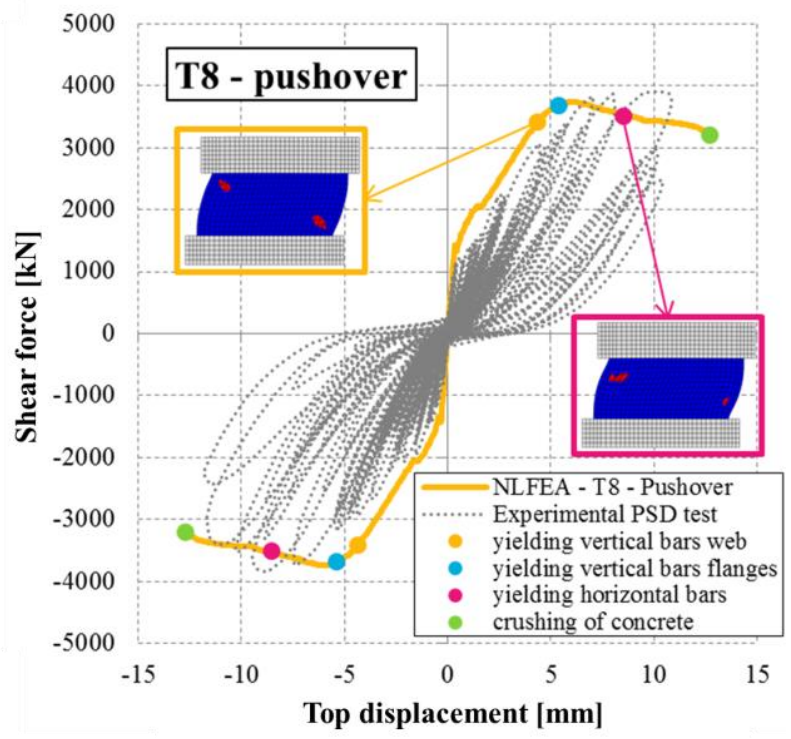

Figure 12 - Static pushover analysis - T8 wall, comparison between NLFEA and experimental results.

\subsection{Static cyclic analyses}

In Figure 13 is reported, for the T6 specimen, the comparison between the cyclic shear force vs top displacement curve obtained by means of NLFEA and the experimental curve. In Figure 13 is also reported the NLFEA pushover curve, Figure 10.

Figure 13 shows that the NLFEA cyclic curve is enveloped by the NLFEA pushover curve. Furthermore the static cyclic curve is quite able to reproduce the experimental results even if further studies are needed to improve the model, especially in the unloading phase. Indeed the aggregate interlock behavior and steel stress strain relations need to be refined in future PARC_CL crack model releases.

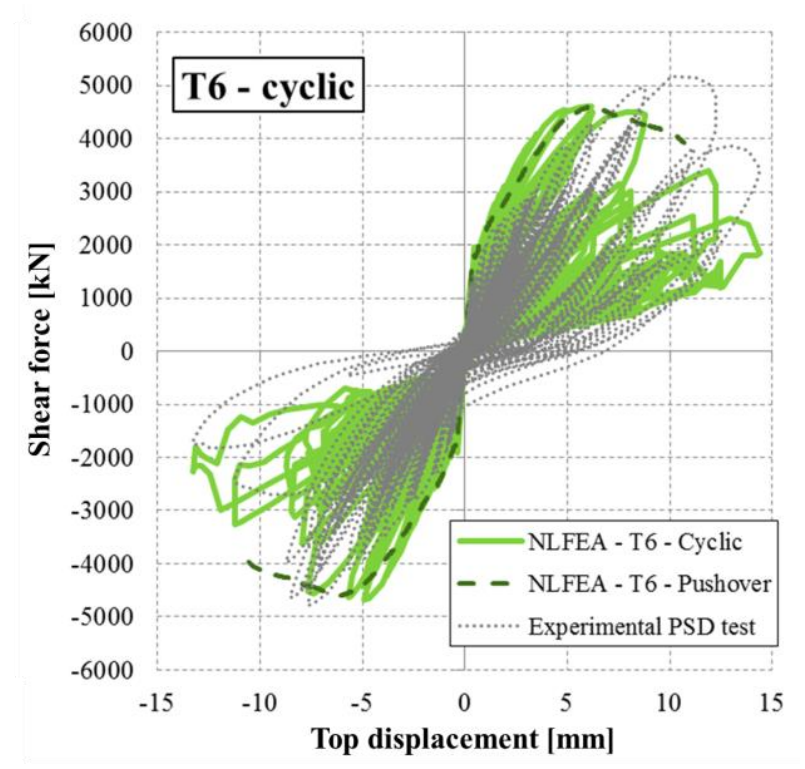

Figure 13 - Static cyclic analysis - T6 wall, comparison between NLFEA and experimental results.

The same conclusions may be obtained analyzing the T8 specimen, reported in Figure 14. Indeed the curve obtained by means of NLFEA is in good agreement with the experimental results while further studies are needed to improve the unloading behavior.

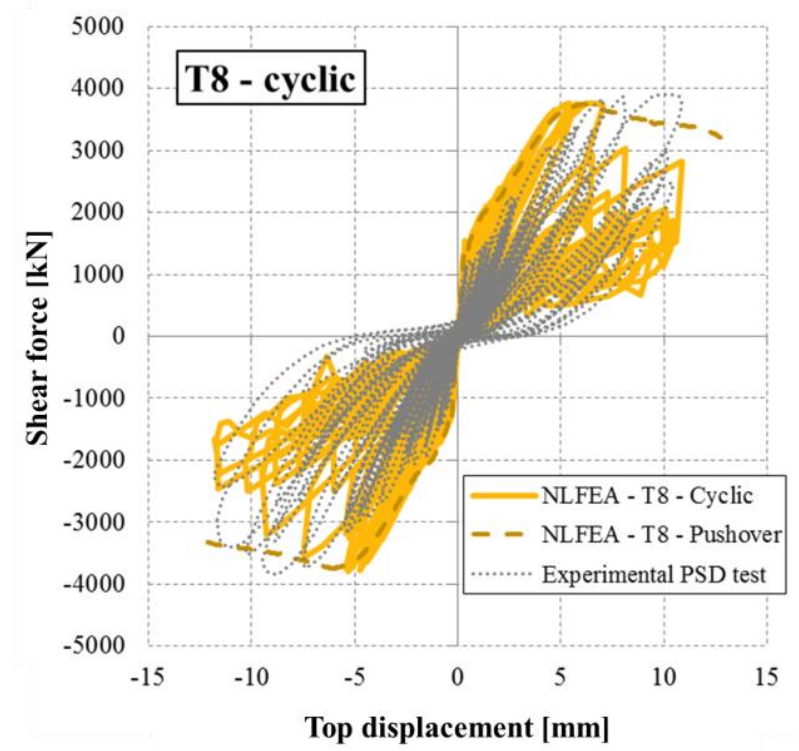

Figure 14 - Static cyclic analysis - T8 wall, comparison between NLFEA and experimental results. 


\subsection{Dynamic time history analyses}

Before running the full dynamic time history analyses, the frequency analyses have been carried out in order to calculate the natural frequency of each specimen and to compare it with the experimental results, Table 5.

From Table 5 it could be seen how the elastic stiffness derived from the natural frequency obtained by means of LFEA, $\mathrm{K}_{\mathrm{NLFEA}}$, is close to the experimental results. Indeed the average value of the ratio between the elastic stiffness derived from LFEA and the experimental value is equal to 0.9 .

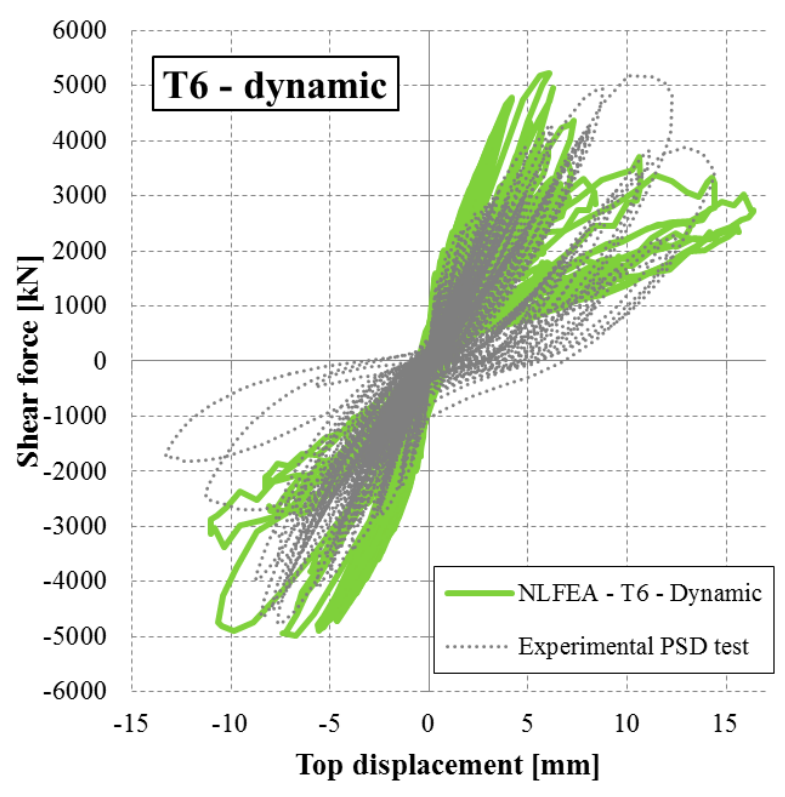

(a)

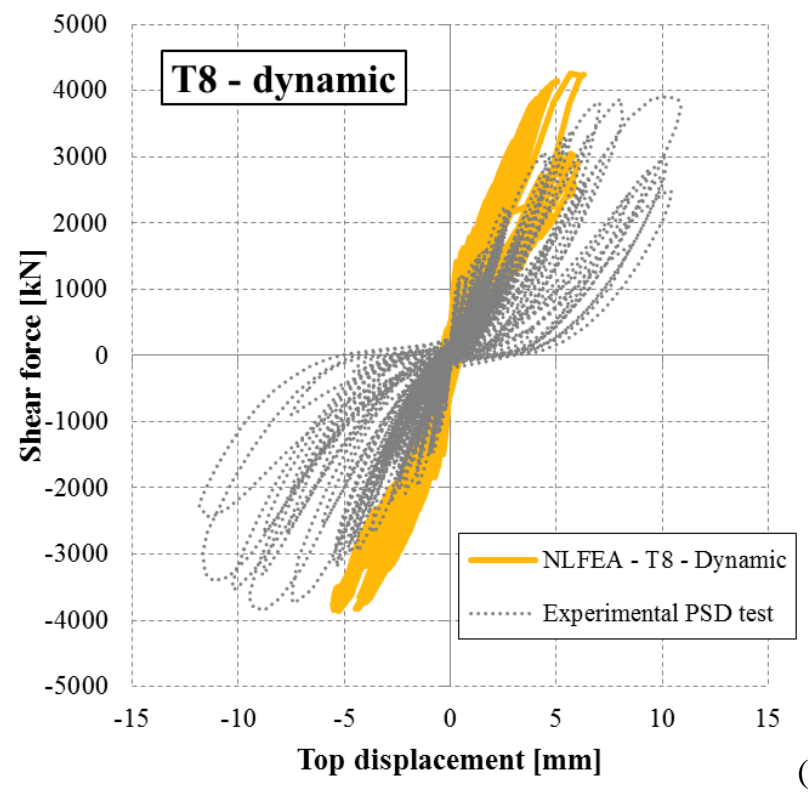

(c)
Table 5 - natural frequency and elastic stiffness: comparison between LFEA and experimental.

\begin{tabular}{|l|c|c|c|c|c|c|}
\hline \multicolumn{2}{|c|}{} & \multicolumn{2}{|c|}{ LFEA } & \multicolumn{2}{|c|}{ Experimental } \\
\hline & M [ton] $]$ & $\begin{array}{c}\mathrm{K}_{\text {NLFEA }} \\
{[\mathrm{MN} / \mathrm{m}]}\end{array}$ & $\begin{array}{c}\mathrm{f}_{\text {NLFFA }} \\
{[\mathrm{Hz}]}\end{array}$ & $\begin{array}{c}\mathrm{K}_{\exp } \\
{[\mathrm{MN} / \mathrm{m}]}\end{array}$ & $\begin{array}{c}\mathrm{f}_{\exp } \\
{[\mathrm{Hz}]}\end{array}$ & $\begin{array}{c}\mathrm{K}_{\text {NLFEA }} \\
\mathrm{K}_{\text {exp }}\end{array}$ \\
\hline$T 6$ & 1252 & 4275 & 9.3 & 5348 & 10.4 & 0.8 \\
\hline$T 7$ & 11272 & 4276 & 3.1 & 5767 & 3.6 & 0.74 \\
\hline$T 8$ & 1252 & 4275 & 9.3 & 4557 & 9.6 & 0.94 \\
\hline$T 9$ & 11272 & 4276 & 3.1 & 3742 & 2.9 & 1.14 \\
\hline \multicolumn{9}{|c|}{ Average } & 0.9 \\
\hline
\end{tabular}

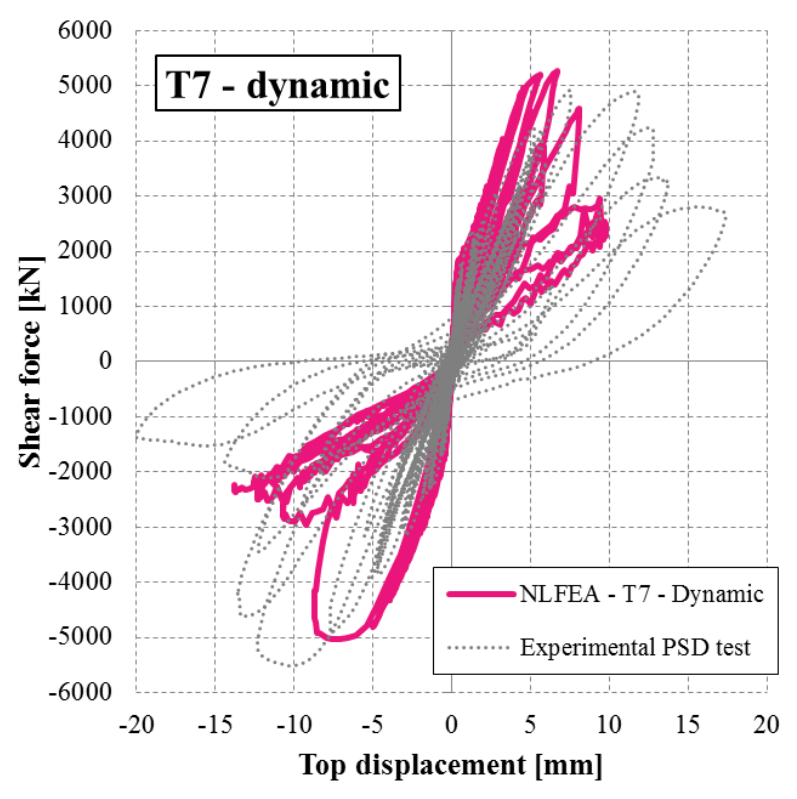

(b)

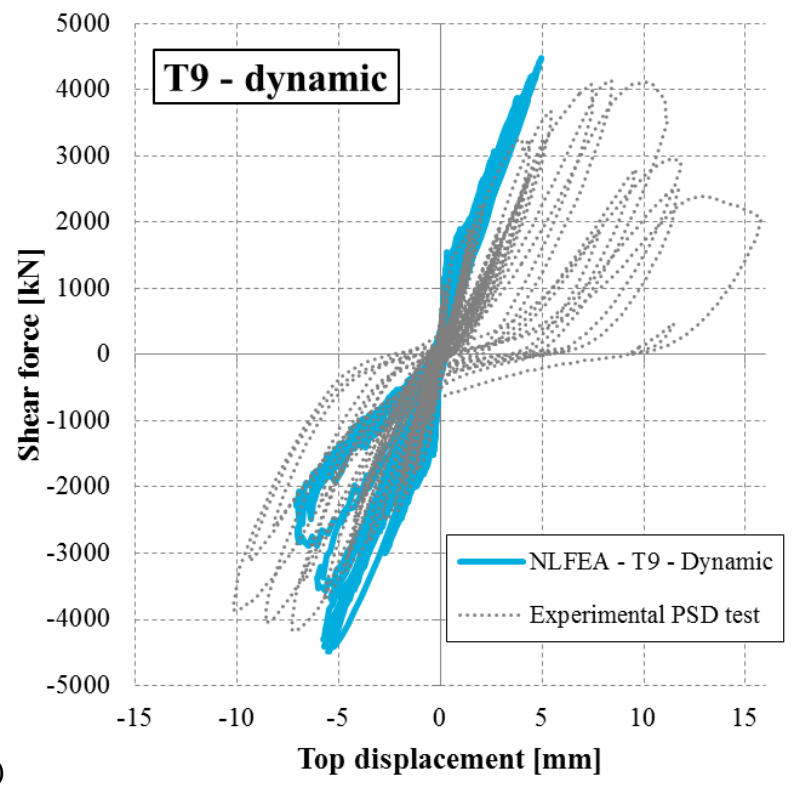

(d)

Figure 15 - Dynamic time histories analyses - a) T6 wall, b) T7 wall, c) T8 wall and d) T9 wall. 
It is important to remark that the LFEA have been carried out assuming a reduced modulus of elasticity of concrete by a factor 0.7 , with respect to the tangent value proposed by $f i b$ - Model Code 2010 [8].

As could be expected the frequency obtained with LFEA is the same for T6 and T8 specimens because the two walls differ in the applied vertical load and in the percentage of steel, which have no influence in the frequency analysis. The same conclusions could be derived for $\mathrm{T} 7$ and $\mathrm{T} 9$ specimens.

Finally, in Figure 15 the results obtained with dynamic time history analyses are plotted and compared with the results of the experimental Pseudo-Dynamic tests.

The results showed in Figure 15 highlight how the prediction of the results in case of Dynamic analysis is not fine as in case of Static Cyclic analysis. The worst estimation of the experimental results could be due to the lack of stiffness proportional damping in the PARC_CL1.1 crack model. Indeed, it is expected that cracking results in a significant drop of the specimen stiffness and consequently in a reduction of the specimen frequency which significantly influence the damping of the specimen as reported in [22]. For this reasons further studies are in progress in order to develop a new version of the PARC_CL model which allows to consider the stiffness proportional coefficient of the Rayleigh's damping.

\section{CONCLUSIONS}

In this paper the behavior of 4 different RC shear walls has been analyzed by means of NLFEA. NLFEA have been carried out using multi-layered shell elements and the implemented PARC_CL1.1 fixed crack model, presented in this paper. Three different kinds of analyses have been carried out (pushover, cyclic and dynamic) and the obtained results have been compared with experimental Pseudo-Dynamic tests.

NLFEA are able to well predict the results for static pushover and static cyclic analyses even if further studies are needed to improve the model in order to consider a more realistic behaviour of $\mathrm{RC}$ members, especially in the unloading phase.

For dynamic analysis the results obtained by means of NLFEA need to be refined. In particular damping calibration may significantly affects the results and further studies are needed for the implementation of proper Rayleigh stiffness proportional damping in the PARC_CL model.

For this reasons a new cyclic model, called PARC_CL2.0, is currently under development in order to improve the cyclic behaviour and to solve the issues highlighted in this paper.

\section{ANKNOLEDGMENT}

The authors would like to thank the OECDNEA and EDF for the organization of the CASH Benchmark and for providing the experimental data.

\section{REFERENCES}

[1] Pegon P., Magonette G., Molina F.J., Verzeletti G., Dyngeland T., Negro P., Tirelli D., Tognoli P., 1998, 'Programme SAFE: rapport du test T6' JRC technical note.

[2] Pegon P., Magonette G., Molina F.J., Verzeletti G., Dyngeland T., Negro P., Tirelli D., Tognoli P., 1998, 'Programme SAFE: rapport du test $T 7^{\prime}$ JRC technical note.

[3] Pegon P., Magonette G., Molina F.J., Verzeletti G., Dyngeland T., Negro P., Tirelli D., Tognoli P., 1998, 'Programme SAFE: rapport du test $T 8^{\prime}$ JRC technical note.

[4] Pegon P., Magonette G., Molina F.J., Verzeletti G., Dyngeland T., Negro P., Tirelli D., Tognoli P., 1998, 'Programme SAFE: rapport du test T9' JRC technical note.

[5] Belletti B., Cerioni R. , and Iori I., 2001. Physical approach for reinforced - concrete (PARC) membrane elements. ASCE Journal of Structural Engineering, 127(12), pp. 14121426.

[6] Belletti B., Esposito R., Walraven J.C., 2013. Shear Capacity of Normal, Lightweight, and High-Strength Concrete Beams according to ModelCode 2010. II: Experimental Results versus Nonlinear Finite Element Program Results. ASCE Journal of Structural Engineering, 139( 9), 2013, 1600-1607.

[7] Guidelines for Non-linear Finite Element Analyses of Concrete Structures. 2012. Rijkswaterstaat Technisch Document 
RTD:1016:2012, Rijkswaterstaat Centre for Infrastructure, Utrecht.

[8] fib - International Federation for Structural Concrete: fib Model Code for Concrete Structures 2010. Ernst \& Sohn, Berlin, 2013.

[9] Whyte C.A., Stojadinovic B., 2013. Hybrid Simulation of the Seismic Response of Squat Reinforced Concrete Shear Walls. PEER Report 2013/02, Pacific Earthquake Engineering Research Center Headquarters at the University of California, Berkeley.

[10] Wood S.L., 1989. Minimum tensile reinforcement requirements in walls. $A C I$ Structural Journal, 86(5), 582- 591.

[11] Martinelli, P, 2007. Shaking Table Tests on RC Shear Walls: significance of numerical Modeling. Ph.D.Thesis, Politecnico di Milano, Italy.

[12] Pilakoutas K., Elnashai A.S., 1993. Interpretation of testing results for reinforced concrete panels. ACI Structural Journal, 90(6), 642-645.

[13] Palermo D., Vecchio F.J., 2002. Behavior of three-dimensional reinforced concrete shear walls. ACI Structural Journal, 99(1), 81-89.

[14] Naze P.A., Sidaner, J.F., 2001. Presentation and Interpretation of SAFE Tests: Reinforced Concrete Walls Subjected to Shearing." Proceedings of SMiRT16 Conference, 12-17 August 2001, Washington, D.C., USA

[15]Mazars J., Kotronis P., Davenne L., 2002. A new modelling strategy for the behaviour of shear walls under dynamic loading. Earthquake engineering and structural dynamics, 31(4), 937-954.

[16]Concrack2: $2^{\text {nd }}$ Workshop on Control of Cracking in RC structures. 2011. CEOS.fr reserach programme, 2011, Paris, France.

[17]Richard B., Fontan M., Mazars J., 2014. Smart 2013: overview, synthesis and lessons learnt from the international benchmark. Ref: SEMT/EMSI/NT/14-037, Document émis dans le cadre de l'accord bipartite CEA-EDF.

[18] Le Corvec V., Petre-Lazar I., Lambert E., Gallitre E., Labbe P., Vezin J.M., Ghavamian S., 2015. CASH benchmark on the beyond design seismic capacity of reinforced concrete shear walls, Proceedings of SMiRT23 Conference, 10-14 August 2015, Manchester (United Kingdom).

[19]Damoni C., Belletti B., Esposito R., 2014. Numerical prediction of the response of a squat shear wall subjected to monotonic loading. European Journal of Environmental and Civil Engineering, 18(7-8), 754-769.

[20] Belletti B., Damoni C., Gasperi A., 2013. Modeling approaches suitable for pushover analyses of RC structural wall buildings", Engineering Structures,57, pp. 327-338

[21]Belletti B., Frassinelli Bianchini M., Stocchi A., 2014. Simulation of Smart 2013 shaking table test with shell elements and PARC_CL modeling. SMART 2013 Workshop, 25-27 November 2014, Saclay (Paris), France.

[22]Pegon P. 1998. Programme SAFE: Présentation générale des essais, $J R C$ technical note.

[23]Sozen M.A., Moehle J.P., 1993, Stiffness of Reinforced Concrete Walls Resisting In Plane Shear, Report No. EPRI TR-102731 Electric Power Research Inst., Palo Alto (CA).

[24] Gambarova P.G, 1983. Sulla trasmissione del taglio in elementi bidimensionali piani di C.A. fessurati." Proc., Giornate AICAP, pp. 141156. (in Italian)

[25]Comité Euro-International du Béton and Fédération Internationale de la Précontrainte (CEB-FIP). (1993). CEB-FIP Model Code 1990 (MC90), Bulletins d'Informations 203 and 205, Thomas Telford, London.

[26] Feenstra P. H., 1993. Computational aspects of biaxial stress in plain and reinforced concrete. Ph.D. thesis, Delft Univ. of Technology, Delft, Netherlands.

[27]Vecchio F. J., and Collins M. P., 1993. Compression response of cracked reinforced concrete. Journal of Structural Engineering, 119(12), 3590-3610

[28]Hilber H. M., Hughes T.J.R., Taylor R.L., 1977. Improved Numerical Dissipation for Time Integration Algorithms in Structural Dynamics. Earthquake Engineering and Structural Dynamics, vol. 5, pp. 283-292, 1977. 